\title{
EL LIBERALISMO SOCIAL DEL PRESIDENTE CLINTON. LA COOPERACIÓN COMO POLÍTICA PÚBLICA
}

\author{
THE SOCIAL LIBERALISM OF PRESIDENT CLINTON. COOPERATION AS A \\ PUBLIC POLICY
}

\author{
José J. Sanmartín Pardo \\ Universidad de Alicante. España/Spain \\ jose.sanmartin@ua.es
}

Recibido/Received: 15/11/2012

Modificado/Modified: 16/01/2013

Aceptado/Accepted: 27/04/2013

\section{RESUMEN}

Bill Clinton recuperó la tradición de liberalismo social que, desde una perspectiva de transversalidad, conformaba su diseño de una Presidencia donde confluían la acción y la respuesta, en forma de política pública, de las demandas sociales. La Administración Clinton hizo de la democracia como un activo social de necesaria incorporación a la idea compartida de Buen Gobierno y servicio público. En este artículo se estudian diversos ámbitos de aplicación del liberalismo social implementado por el Presidente Clinton. Las políticas públicas constituyeron el centro de su acción de Gobierno, mediante la implementación de una elasticidad que abarcaba la atención al ciudadano y la defensa de su dignidad como miembro activo del demos. El despliegue de lo social como parte del patrimonio moral de la democracia.

\section{PALABRAS CLAVE}

Política social, cooperación, liberalismo, Clinton.

\section{SUMARIO}

1. Breve introducción. 2. La transversalidad de la política social. 3. La cooperación como ejemplo moral. 4. La cooperación como política pública. 5. Una inversión de futuro. 6. Conclusiones. Bibliografía.

\begin{abstract}
Bill Clinton regained the tradition of social liberalism that, from an open minded perspective, shaped their design of a unique Presidency where action and response converged in the form of public policy for social demands. The Clinton administration operated democracy as a social asset of indispensable addition to the shared idea of Good Government and public service. In this paper we study various fields of application of social liberalism implemented by President Clinton. Public policies were the focus of government action, by implementing an elasticity covering citizen services and upholding their dignity as an active member of the demos. The deployment of social policy as a part of the moral heritage for democracy.
\end{abstract}

\section{KEYWORDS}

Social policy, cooperation, liberalism, Clinton. 


\section{CONTENTS}

1. Brief introduction. 2. The mainstreaming of social policy. 3. Cooperation as a moral example. 4. Cooperation as public policy. 5. Investment in the future. 6. Conclusions. References.

\section{BREVE INTRODUCCIÓN}

La retórica política implementada por William Jefferson Clinton como Presidente de los Estados Unidos de América, arrojó unas afinidades y unas disimilitudes -tan interesantes las unas como las otras- respecto a lo realizado por anteriores dirigentes en materia de política social en su país. De hecho, la cooperación adquirió en su discurso institucional la categoría de concepto ético; específicamente, la colaboración transnacional, entendida como deber moral y practicada como solidaridad colectiva, fue una esfera cultivada con esmero en su comunicación política por las implicaciones morales, culturales y democráticas que comportaba. De ahí que el propio Presidente subrayase la "importancia del intercambio de cooperación y de información en el área de la ciencia y de la tecnología" (Clinton, 1994b). La habilidad natural de Clinton consistió sobre todo en desplegar e interrelacionar el sustrato yacente a los distintos campos (desarrollo, bienestar, democracia, sociedad de la información, nuevas tecnologías) bajo el común denominador de las relaciones internacionales.

Se realiza aquí un estudio sobre la innovación -logro nítido, como veremos- que Clinton aportó a la tradición política estadounidense sobre cooperación, así como un análisis en perspectiva sobre sus distintas técnicas para hacer llegar a la sociedad programas sociales donde la cooperación siempre tuvo un lugar relevante. El Presidente desarrolló unos conectores inteligentes entre su discurso y el auditorio; de tal manera, además, que la cooperación emergía no como una rémora social o económica, sino como un factor de dinamización y progreso en el marco de una economía global.

La sagacidad política de Clinton le impulsó a utilizar la cooperación como una idea redentora de la sociedad. También Nigel Hamilton ha reconocido la habilidad del Presidente para impulsar una agenda institucional en los aspectos que constituían su línea política. De hecho, este autor atribuye también la asimilación de la presidencia Clinton a la imagen glamurosa legada por la estela de Kennedy; una intencionalidad política constatable desde el primer momento. Ya en su toma de posesión, el Presidente Clinton insertó su discurso en el idealismo de Camelot, buscando para sí lo mejor de la herencia kennedyana. "Viejos washingtonianos, recordando la inauguración presidencial de JFK, quedaron sorprendidos, incluso impresionados, por la genuina y evidente efusión de esperanza y buena voluntad" (Hamilton, 2007:7). El mensaje público del Presidente Kennedy fue una influencia igualmente visible en su posición institucional; bajo la Administración Clinton, se procuró dotar -aún con irregular resultado- a los AmeriCorps de una función simbólica para canalizar el interés de jóvenes norteamericanos a la hora de realizar cooperación al desarrollo. De ahí sus viajes a países en vías de desarrollo (en particular, sus memorables visitas a países africanos) donde era posible ejecutar una simbiosis efectiva entre las palabras -que articulaban su ideario sobre el tema- y una acción decidida -que fuese implementada como solución progresiva a los problemas acuciantes que la Cooperación al Desarrollo venía a combatir-. La solidaridad como terapia salvífica de una sociedad. La extensión de la generosidad convertida en activo moral -y signo 
identificador- de una comunidad democrática.

\section{LA TRANSVERSALIDAD DE LA POLÍTICA SOCIAL}

La singular mixtura implementada por William Jefferson Clinton entre cooperación y desarrollo hizo que esa fuerza combinada, en sus manos, se erigiese en una efectiva línea para reforzar el argumentario presidencial a favor de la solidaridad y el compromiso; el despliegue democrático requerido a toda sociedad civil moderna, donde el avance de un orden de libertad apareciese consolidado con la implantación -gradual, segura- de nuevos derechos y servicios en el Estado del Bienestar. La libertad se constituía, pues, como un factor cohesivo en los programas gubernamentales; los discursos presidenciales también aparecían, de manera coherente, enfocados hacia la cooperación, la colaboración, el entendimiento. Aun así, con astucia política, Clinton evitó incurrir en el error -demasiado habitual, y propio de líderes mesiánicos- de emerger más como un Presidente decantado hacia la injerencia que en fomentar la amistad entre pueblos y gobiernos; de igual a igual, sin jerarquías ni desplazamientos. La Declaración firmada por Rusia y Estados Unidos, bajo el título Partnership for Economic Progress: Joint Statement on Principles and Objectives for the Development of Trade, Economic Cooperation, and Investment, comenzaba con el enunciado siguiente:

Believing that strong economic ties and cooperation can contribute significantly to the building of strong, friendly relations and acceleration of the development of free markets, economic growth and job creation in both countries (Clinton, 1994c).

Desde la Casa Blanca se ejecutó una concepción de la Cooperación al Desarrollo, que también implicaba la ayuda mutua; todas las partes aparecían igualmente concernidas, dado que los Estados Unidos -como país donante- recibía a su vez dividendos extremadamente positivos al mitigar el sufrimiento de las naciones pobres. "Todos ganamos, pues la vida es obligación moral y derecho social", transmitía Clinton en su retórica política.

In other words, in order to isolate and undermine the terrorists, there must be a political dialog and a political settlement, not with terrorists but with those who are willing to seek a peaceful resolution (Clinton, 1999).

La cooperación debe realizarse desde un plano de igualdad en el trato, sin paternalismos caducos ni gestos de autosuficiencia por parte del Estado. Las giras de Clinton por distintos países africanos le permitieron consolidar su figura de estadista, al tiempo que -en el ámbito doméstico- ese halo de humanitarismo aflojó en algo la presión del "escándalo Lewinski", aunque sí le granjeó, todavía más, la simpatía quasi personal de sus conciudadanos afro-americanos.

Más allá de una remozada corrección política, el Presidente intentó crear lazos perdurables entre Estados Unidos y los países en vías de desarrollo, mediante la sanación del agravio comparativo, así como restañando las injusticias históricas acumuladas con el paso del tiempo. Una reparación moral de la cual Clinton fue un convencido practicante. La baza mejor era, claramente, el futuro. Al brindar un porvenir a los pueblos africanos que sufrían el azote de hambrunas periódicas y guerras cíclicas, Clinton también curaba a su propia sociedad, presentándose como el Rey Patriota que Bolingbroke diseñara. Un 
líder que conforta en las aflicciones y soluciona los problemas. Compelidos estamos al cumplimiento de las normas morales que están por encima de nuestros egoísmos individuales, y que atañen directamente a un obligacionismo ético que el Presidente asumió como propio en su discurso político. Hecho este que, además, aparecía envuelto con un mensaje deliberadamente práctico; una manera de vincular la consecución de tan loables objetivos mediante la rentabilidad, incluso material y económica, de los mismos.

Desde esa perspectiva, quedan contextualizadas las apelaciones presidenciales al excelente porvenir de las inversiones en África, o en los países de la antigua Unión Soviética. Clinton se convirtió en una figura totémica, que trasciende el momento presente para avanzar -y hacer progresar al resto de la comunidad política- en pos del sueño irredento de bienestar, paz y seguridad. La cooperación emergía así como un mecanismo de amplia resonancia mediática, con efectiva utilidad política, que el Presidente supo manejar con cuidadosa maestría. Sus baños de multitudes en África, su compromiso social, su imagen de líder entregado a la causa democrática, tuvieron un efecto taumatúrgico en la rehabilitación iconográfica -y ética- de su Presidencia ante el pueblo norteamericano. Un mandatario que disponga, también, de verdadera capacidad de liderazgo siempre conservara recursos auxiliares para afrontar las crisis y los problemas sobrevenidos (Edwards y Wayne, 2009).

Clinton manifestó una habilidad única a la hora de vender futuro. Su capacidad dialéctica en este campo era extraordinaria y obedecía, significativamente, a la inspiración de la mejor tradición retórica del presidencialismo norteamericano. Una influencia evidente fue no sólo el acervo del Partido Demócrata (Kennedy, en particular), sino también de otros presidentes que marcaron su juventud como Richard Nixon. Tanto éste como Kennedy, aún con estilos disímiles, podían motivar a sus auditorios impulsando actuaciones en dirección de futuro, proyectando hacia delante toda iniciativa que partía del tiempo presente. Así, en una obra posterior, el propio Nixon continuaba explorando ese lado mágico de la retórica presidencial que Clinton también utilizó para sí como defensa de la cooperación.

Nos encontramos en este mundo para algo más que la autosatisfacción hedonística.

Nos hallamos aquí para hacer historia, no para ignorar el pasado, no para destruir el pasado, no para volver al pasado, sino para avanzar y elevarnos de tal modo que abramos muchos horizontes para el futuro (Nixon, 1989:349).

La experiencia era, para Clinton, base indispensable para gestionar políticas de cooperación. En fecha tan temprana como el 26 de abril de 1993, su alocución dedicada con motivo de la Nomination for Ambassador to the Organization for Economic Cooperation and Development elogio a David Aaron como "an experienced and accomplished foreign policy hand" (Clinton, 1993a). Al mismo tiempo, en su "Nomination for Assistant Administrators at the Agency for International Development" también ponderó la experiencia "en sus campos" de Thomas Dine y Jill Buckley. La operatividad solvente, el pragmatismo constructivo -en el sentido de to know how-eran para Clinton títulos exigibles a sus colaboradores en materia de cooperación; más allá incluso de la capacidad de negociación o la popularidad mediática. La Cooperación al Desarrollo no permite dispendios ni juegos malabares; es preciso ir a lo seguro, este es el mensaje presidencial. La urgencia de esta ayuda exige lo mejor de cada uno de nosotros. Una actividad humanitaria, pero también con incidencia sobre el tejido social e industrial de los países concernidos (donante y receptor). Y, de manera calculada, la permanente idea de 
complementariedad que aporta la cooperación. Clinton subrayó este aspecto en prácticamente cada oportunidad.

\section{LA COOPERACIÓN COMO EJEMPLO MORAL}

En buena lógica, la visión de Clinton sobre lo que debía ser la Cooperación al Desarrollo, se extendía más allá de los límites marcados por el interés nacional. El Presidente demócrata procedió a limitar la influyente "doctrina Kissinger”, según la cual la política exterior de Estados Unidos debe regirse, casi exclusivamente, en la defensa de su interés nacional; definido éste la mayoría de las veces por su vinculación a la protección de los intereses económicos $\mathrm{y}$ estratégicos promovidos por las grandes empresas o corporaciones industriales. En definitiva, el Presidente Clinton no desplazó lo económico a favor de la ética, sino que intentó conciliar ambos elementos en una difícil coyuntura. Desde su ideario, Estados Unidos, como país democrático, tenía un compromiso moral adquirido desde su constitución. La defensa de la libertad y la seguridad de las personas dentro de sus fronteras; y fuera, al menos, evitar la conculcación de los Derechos Humanos, siendo éste el criterio rector a seguir por la política exterior.

En sus memorias, el propio Clinton -entonces atribulado por los escándalos que se cernían sobre su persona y que amenazaban su obra política- ha reconocido lo impresionado que quedó en su visita a Ruanda. Allí conoció a supervivientes del genocidio practicado por radicales hutus en 1994. Entre ellos, el sobrecogedor testimonio de una señora que, tras ser gravemente herida a machetazos fue dejada por muerta; sin embargo, despertó en el vómito de su misma sangre, rodeada de cadáveres, (entre ellos, su marido y sus seis hijos). Ella relató a la señora Clinton que si su vida había sido salvada por Dios, era porque alguna razón existía para ello. A raíz de esta trágica vivencia relatada por una superviviente, el Presidente comprendió mejor la naturaleza humana, y el sentido de la vida. La superviviente a una tragedia indecible proporcionó al hombre más poderoso en la Tierra una lección que nunca olvidaría. "Me quede abrumado; aquella extraordinaria mujer había hecho que mis problemas pareciesen patéticamente pequeños" (Clinton, 2004a:782). El sufrimiento y el dolor que sintamos, la angustia ante situaciones sobrevenidas que escapan a nuestro control, toda clase de problemas y dificultades que asalten la aparente tranquilidad de nuestro hogar, sólo demuestran, una vez y otra también, la fragilidad de la existencia humana. Cuando estos hechos arrecian, la única solución es volcarse en los demás: ayudarles, y ser ayudado. Dios llama a nuestra puerta para que el egoísta que hay en cada uno de nosotros nos abandone definitivamente, dejando salir al espíritu bondadoso que anida en nuestro interior. Clinton se curó a sí mismo a través de la mediación de una fe transformada en verdadera fuerza interior. La solidaridad que pedía para otros era una metáfora de la generosidad que reclamaba para él mismo. Y siempre, su pensamiento: sólo ayudando, podemos ayudarnos a nosotros mismos (Clinton, 2007).

A pesar de las críticas recibidas desde sectores que le eran hostiles, conviene no desmerecer el significado de su asistencia a una celebración eucarística en África en la que participó en la comunión. Igualmente se produjo una gradual y tácita recristianización de sus valores, conforme ganaba apoyo la oposición conservadora favorable a su impeachment. El Presidente, que asumió en un segundo tiempo sus errores, se consideraba a si mismo como un pecador arrepentido, mas perseguido y demonizado por el establishment y la llamada "buena sociedad". Su única esperanza estaba en el perdón de 
Dios y la generosidad de su pueblo. Hacia ambos se dirigió. Clinton comprendió que la escala de valores cambia sustancialmente de una parte a otra de la sociedad, del país, del mundo. Todos hermanos, pero desconocidos entre sí.

Clinton figura por derecho propio entre los mandatarios estadounidenses más cooperativos de la segunda mitad del siglo XX. De ahí que la situación africana, como otras partes del mundo aparentemente abandonadas a su suerte, generase en Clinton una reflexión que arroja luz sobre la retórica presidencial en este campo, al decir

Reconozco que los Estados Unidos y la comunidad internacional no habían actuado lo suficientemente deprisa para detener el genocidio o para evitar que los campos de refugiados llegarán a convertirse en refugio para los asesinos (Clinton, 2004a:782).

La necesidad de institucionalizar la cooperación era, en su visión de las cosas, un hecho necesario e inaplazable. Para Clinton los acuerdos -siempre de igual a igual- deben impulsar ideas y, sobre todo, principios. La materialización de valores morales que operan en política carecen de sentido si fueran privados de toda ejecutividad.

Both sides agree to continue with exchanges of information in the area of science and technology and to cooperate in identifying opportunities for scientific and space research collaboration. They agreed to conclude a bilateral Science and Technology Agreement to formalize government-to-government cooperation and to establish a coordinating mechanism to foster bilateral science and technology cooperation (Clinton, 1994a).

La cooperación se desenvuelve de una manera creciente, y con criterio institucional. Es preciso afirmar los pasos dados mediante la creación de organismos que velen por el cumplimiento de los acuerdos, y provean la institucionalización de un sistema ágil y efectivo de cooperación. De alguna manera, Clinton recuperó para la cooperación el viejo axioma nixoniano de progreso equilibrado en política exterior. Así, en su análisis de la perestroika, el entonces retirado Presidente hizo patente su visión del problema estratégico:

Si Gorbachov llegara a modificar internamente la Unión Soviética y apaciguara su política exterior, Occidente lo aplaudiría. Pero hemos de asegurarnos, hemos de esperar a que efectúe estos cambios antes de reconocérselos. No debemos premiarlo con una modificación de nuestra estrategia frente a él en tanto él no cambie la suya frente a nosotros. No puede tenerlo todo: una relajación de las tensiones con Occidente mientras sigue emprendiendo acciones que hacen peligrar los intereses occidentales (Nixon, 1989:226).

La cooperación multilateral, así como la ayuda al desarrollo, comportaba para Clinton un esfuerzo de todas las partes concernidas; socios en pos de un objetivo común. Todos debían ser ganadores en un proceso pautado donde los cambios se ejecutaban conforme a las circunstancias, siempre variables, de cada momento histórico. El Presidente adaptó su consabido pragmatismo al objeto de implantar cambios, y modular otros ya incorporados a la sociedad, pero mantuvo el idealismo progresista en cuanto a la definición de los fines últimos del sistema político: las políticas de solidaridad, de cooperación, quedaron afianzadas como parte sustancial del acervo cívico de la Presidencia, y de la sociedad (Nelson, 2005). Los programas a favor del Tercer Mundo ganaron mayor flexibilidad, hasta adecuarse a cada eventualidad. Aprender de los errores propios y ajenos. Los 
capítulos ingratos de su pasado electoral aportaron Clinton la instrucción en esta materia: la derrota de George McGovern y los demócratas frente a Nixon en las elecciones presidenciales de 1972, le hizo reflexionar sobre las causas profundas de la reelección del candidato conservador. No se puede pretender cambiar todo a la vez. Modulaciones, gradualismo, matices, en un discurso integrador y positivo. Que el ciudadano pueda ver, y sentir, que el Gobierno piensa en sus necesidades, sin desatender otras obligaciones materiales y morales- como la ayuda al desarrollo.

Ganar las elecciones como un progresista requiere mucho esmero y disciplina al elaborar y presentar un mensaje y un programa que da a la gente la confianza para cambiar de dirección. Nuestra sociedad sólo puede absorber una parte del cambio de una vez (Clinton, 2004:200).

\section{LA COOPERACIÓN COMO POLÍTICA PÚBLICA}

El Presidente comprendió cabalmente que era necesario realizar un despliegue asertivo de la cooperación internacional, en el sentido de dotarla de un contenido familiar para el ciudadano medio (Barber, 1992). Se imponía la necesidad de desarraigar la idea de que la ayuda destinada para África o Asia fuera un hecho extraño, sino que debía aparecer vinculada al propio interés de cada norteamericano. Al mismo tiempo, el Presidente consideraba necesaria una mayor implicación del sector privado norteamericano en la cooperación con el Tercer Mundo. La Administración puede impulsar determinados programas y, como verdadera proeza, también generar riqueza pero es imposible cargar sobre el presupuesto público el peso de la regeneración económica de varios países. Clinton cautivó a los emprendedores para que realizasen la tarea de un verdadero gestor: producir nuevas oportunidades para todos, en ambientes aparentemente incómodos pero agradecidos, e igualmente abiertos al aprendizaje.

My Administration understands that, in a time of shrinking Federal funding, any strategy to support trade and development in Sub-Saharan Africa will need to rely heavily on increased U.S. commercial involvement in the region. American firms and workers stand to gain a great deal by doing business in Africa. By playing an active role, both in direct commercial relations in the region and in cooperation with the United States Government, the private sector will generate significant benefits for themselves and for the United States and Sub-Saharan Africa as a whole (Clinton, 1996a).

La idea de vencer las dificultades, propia de un corredor de fondo, se activó en el discurso de Clinton como rasgo distintivo. La vida es competitividad, de acuerdo, pero también para ayudar, para socorrer, que es la manera más efectiva de cumplir nuestro deber hacia los demás. Clinton recuperaba para sí los preceptos político-éticos de John Stuart Mill: la ayuda al prójimo es una obligación inherente al liberalismo, no un complemento que pueda ejercerse o no de acuerdo al criterio potestativo de cada uno. Un compromiso de obligado cumplimiento por parte de los miembros de la comunidad. Clinton recuperó la añeja concepción de bien común que formulara John Stuart Mill; el liberalismo social exige la propia responsabilidad a la hora de practicar la solidaridad con los que menos tienen. La conciencia social que el Presidente reconoce en My Life como valor admirable del catolicismo, era para él un hecho material, y no meramente un dogma 
político, o una utopía irredenta. La utilidad de la cooperación, de la justa colaboración entre países, aporta unos beneficios materiales para una parte, y un cúmulo de estímulos para la otra. Estados Unidos también gana al ayudar a quien lo necesita, afirma la retórica presidencial. Autoestima, respeto como nación, unidad en torno a una causa justa, cohesión social, liderazgo democrático en Occidente, etc. Entre los países libres, el poder de la influencia se gana a pulso, mediante la realización de hechos meritorios, no por vía de la fuerza bruta.

Los discursos de Clinton propendían a la búsqueda de las razones de cada fenómeno social y/o político. Basada en la lógica, la retórica presidencial emergía como baluarte de los Derechos Humanos y, por tanto, de la dignidad de la persona. Sobre este círculo de excelencia, Clinton insertó su apología de lo social como divisa moral de su Presidencia; la cooperación como herramienta para la mejora de la democracia. La justicia social como expresión de libertad y dignidad. La Doctrina Clinton arraigaba su operatividad en el Democratic Enlargement que formuló el Presidente, es decir, la difusión de la democracia y la economía libre como elementos nucleares -mutuamente complementarios, plenamente necesarios- de un remozamiento de la política exterior; el diálogo abierto y un calculado multilateralismo compensarían el hecho de que Estados Unidos hubiese quedado como la única superpotencia. En el fondo, Clinton pretendía aplicar un programa que liberalizase tanto la política como la producción, expandiendo el bienestar de manera general e incondicionada.

La posición del Presidente obedece a un planteamiento vocacionalmente racionalista e idealista. Clinton trabajaba por la constitución -que no restauración- de un moderno orden natural entre pueblos y Estados; para ello resulta indispensable el equilibrio que permita la conciliación de objetivos, recursos e intereses en pos de un fin común: la estabilidad. De ahí el impulso de criterios para la validación moral por parte de los agentes sociales afectados por una policy presidencial: la cooperación a favor de países en vías de desarrollo, o en defensa de causas humanitarias, por ejemplo, comportaba no sólo una obligación ética, sino también un deber económico. También aquí, la habilidad del Presidente residió en lograr la integración de las partes en un todo que les vinculase y les vehiculase. Eficiencia y eficacia. En su tentativa de modernizar el concepto de cooperación, el Presidente también aplicó metodología propia del management (Pfiffner, 1999). La cooperación debe generar dividendos, y rendir cuentas. Un modelo de colaboración donde la transparencia y la lealtad entre las partes prevalece sobre otras ecuaciones.

The United States and Ukraine recognize that defense conversion is a priority task for each country and that cooperation will enable each country to meet that task more efficiently and effectively (Clinton, 1994a).

Como elemento indispensable de su retórica política, Clinton siempre operaba -en sus discursos sobre cooperación- desde la perspectiva mejor; colaborar, ayudar, era presentado como un proceso de mejora mutua entre las partes intervinientes. Un acto de equidad, y un deber patriótico de los Estados Unidos. El Presidente siempre dio soporte a la asistencia de países en vías de desarrollo, al alivio material para situaciones de emergencia (hambrunas, guerras, tragedias naturales, accidentes masivos, etc.), así como actos de generosidad que el pueblo estadounidense condividía. Una metáfora, una idea que asentaba la necesidad de desplegar políticas de solidaridad. Resultaba incoherente, sostenía Clinton, ayudar únicamente al extranjero abocado a una situación de desprotección, dejando de lado al 
compatriota en análogo estado. Es preciso extender los programas de sanidad, entre otros, a favor de las personas que sufren y padecen. Los déficits sanitarios, por ejemplo, deben ser subsanados mediante una sólida red de asistencia social. De esta manera, el Presidente podía referirse a un "exhaustivo programa de cooperación" (Clinton, 1994b). Esa voluntad totalizadora, de vertebrar todos los factores, reuniéndolos en torno a la modalidad de hacer política internacional, se erigió en mascaron de proa de la imagen presidencial en esta materia.

Expanded bilateral economic ties and commercial cooperation can make a significant contribution to strengthening U.S.-Ukrainian relations and developing free markets, economic growth and jobs in the two countries (Clinton, 1994b).

En Clinton, la cooperación se formulaba como una respuesta lógica -desde el criterio de la proporcionalidad- a los desafíos de su tiempo histórico. Una propuesta donde se marcan los objetivos de manera clara. Al mismo tiempo, el Presidente también proveía de tranquilidad psicológica a la siempre vulnerable sociedad civil que vertebraba la democracia; en un mundo cada vez más inestable, donde las grandes referencias ideológicas se hallan en crisis y las amenazas locales se troncan en peligros globales, la apelación -y la práctica- a los elementos cohesivos, aquello que compartimos, podía retribuir con dividendos benéficos al conjunto de la sociedad. En la visión de Clinton, las ideas de cooperación y solidaridad constituyen, por tanto, piezas fundamentales para mantener una posición política en defensa de la libertad individual y de la democracia de todos.

We agree on the need to strengthen the international financial system and national financial sectors in order to capture the full benefits of international capital flows and global markets, minimize disruption and better protect the poorest and most vulnerable. It is important that all in the global economy play their part to promote sustainable growth and financial stability, by pursuing economic policies aimed at strengthening their national economy and enhancing their economic performance (Clinton, 1998a).

Trabajar juntos, en pie de igualdad, pero sin abandonar su carácter competitivo: ejerce mayor influencia aquel que aporta más a la hucha de la cooperación. El esfuerzo de cada uno significa la entrega hacia los demás. En su configuración de un nuevo heroísmo social, Clinton supo activar la energía creadora de la comunidad; de tal manera, además, que cada persona se sintiera protagonista de su destino, sin desmerecer de su pasado o condición de partida. Y ello, siempre, en el marco de unas reglas de juego que debían ser las propias de un Estado de Derecho.

They work together to promote greater international cooperation and coordinated effort to combat terrorism by all legal means and in all relevant bilateral and multilateral for a-from the Transatlantic Dialogue to the United Nations (Clinton, 1998b).

Este silogismo clintoniano desbarataba el argumentario tradicional por el cual Estados Unidos tenía primacía originaria, por vía de un supuesto derecho inalienable, a liderar al mundo occidental. La exigencia de acción implicaba también la necesidad de movilizarse ante cada catástrofe, de luchar contra la tragedia; en todas partes, en cualquier momento. El aislacionismo era parte del lastre del pasado que debía superarse; la posición de Clinton 
fue siempre diáfana al respecto. Aparte de que la protección de los intereses económicos, la defensa de las empresas ya no constituían la columna vertebral sobre la que asentar la política exterior norteamericana. Aquellas no son opciones en la aldea global. Clinton lo comprendió inmediatamente para, de manera coherente, auspiciar la seguridad global que precisa una mentalidad igualmente integral: abordar los problemas en las fases tempranas, cuando el coste de resolverlos todavía es asumible, no esperando a que las crisis entren en una fase irreversible; porque es nuestro mundo y son, estén donde estén, nuestros problemas.

We reaffirm our commitment to development cooperation, which has among its main objectives the fight against poverty, the creation of conditions favorable to economic growth and sustainable development, and the participation of the most vulnerable in this process. The prompt and generous U.S. and EU responses to the devastation caused by Hurricane Mitch in Central America are an example of our commitment. We will seek to ensure good coordination of international donor assistance to respond effectively to crises (Clinton, 1998a).

La innovación, la implementación de otras vías que abran puertas a la socialización del bienestar y al desarrollo de los pueblos. Buscar nueva formas de cooperación (Clinton, 2000); tejer una tupida red de vínculos entre las sociedades e industrias de distintos países, para crear unos intereses compartidos que, desde la base, facilitasen el acuerdo, la estabilidad, además de la regeneración democrática y económica. Pero en la cima de esa fábrica cooperativa... la solidaridad, el compromiso, como política de la democracia y afirmación de la justicia. La dignidad de la persona, siempre.

\section{UNA INVERSIÓN DE FUTURO}

El apoyo del entonces gobernador de Arkansas a Michael Dukakis, para encabezar el ticket demócrata en 1988, le granjeó respeto entre dirigentes históricos del partido. Clinton lograba así sellar un pacto de caballeros con figuras señaladas del establishment demócrata como Mario Cuomo o el senador Kennedy. La nominación posterior de Bill Clinton por parte del Partido Demócrata significó también el triunfo de una esperanza kennedyana. Esa idea de renacimiento, de reconstrucción integral de un país, de una sociedad, de una ilusión compartida por todos, fue hábilmente utilizada por un Clinton apenas conocido como político regional para difundir su imagen como líder nacional. El salto desde la política regional para competir políticamente en Washington, conceder una entrevista en Nueva York, o pronunciar un discurso en Los Ángeles, exige una transformación igualmente profunda. La retórica es parte del cambio; se necesita un nuevo idealismo -práctico, útil, próximo y reconocible para todo ciudadano- capaz de servir como soporte a esas ideas concretas, directas, que sedimentan un buen discurso político.

La campaña de Clinton para lograr la nominación demócrata en 1992 y, luego, la propia táctica electoral que le otorgó la Presidencia, demostró que el gobernador sureño deseaba conferir a su campaña una imagen meritocrática del ascenso político. En un sistema democrático, la consecución de una victoria debe reunir, al menos, una doble dimensión: política (electoral) y ética (moral). De lo contrario, ese liderazgo quedaría sometido a fuertes zozobras, no sólo parlamentarias. Con sagacidad cartesiana, Clinton aplicó de manera crecientemente sólida desde 1995 una programación gubernamental cuyo 
mascaron de proa no eran exclusivamente los grandes eventos, sino también la atención a las demandas de los ciudadanos de mayor proyección social. Es por ello que Clinton recomendaba a sus asesores la conversión de las encuestas en política; la transformación de los estados de opinión en programas de gobierno fue un activo de su Administración. La búsqueda de la perfección como quimera política tuvo en la acción pública del Gobierno federal a un consumado ejecutante.

Conectar su responsabilidad institucional a los deseos del pueblo. Toda decisión, cualquier iniciativa adoptada por el Presidente, debe aparecer con su correspondiente refrendo popular. La motivación de los hechos, la legitimación de las actuaciones alcanzó en Clinton una cima de eficacia. De manera resolutiva, el Presidente supo transmitir el mensaje de que el Gobierno se realiza entre todos, como obra colectiva que es; desde esta perspectiva de filosofía moral, el mandatario desempeña una tarea al servicio de su comunidad política, que le presta un auxilio indispensable. Se gobierna desde el corazón mismo del pueblo; nunca a distancia. La pérdida de contacto con la realidad significa, inevitablemente, la erosión de nuestro sentido de la realidad. Clinton comprendió los errores ajenos, también los propios -dejando aparte su reluctancia en la primera etapa del escándalo Lewinsky a reconocerlos-; aquel fue un camino empedrado hasta depurar un estilo retórico verdaderamente proactivo que canalizase a su favor las sinergias que suscitaba el mensaje político. En este contexto, el Presidente podía presentar cada una de las actuaciones de su Gobierno como una respuesta clara y concreta a la necesidad real, puntual, que fuera expresada por algún sector de la sociedad. Una carencia que, con revestimiento quasi taumatúrgico, era ofrecido por la Casa Blanca en el altar del patriotismo cívico, el idealismo democrático y la utilidad política. Una utopía construida y alimentada de manera continua- sobre la base de provisión de hechos, resultados, mitos o esperanzas.

For several months last year, individuals and groups of citizens had been writing to the National Archives to inquire whether the historic document would be exhibited over the new year holiday in honor of its anniversary. After considering the matter, the National Archives decided to arrange an exhibit (Clinton, 1993b).

La polémica debe evitarse como mayor enemigo de la verdad política. Un líder jamás debe aparecer rodeado de dudas laminadoras, ni siquiera bajo la forma de sombras remotas, acerca de su gestión; la solución a ello no es el vano ocultamiento, sino la claridad y la transparencia como dividendos relevantes a la hora de afrontar una situación de crisis. Como enseñó Clinton, lo verdaderamente importante no siempre es la causa en sí del conflicto, sino la gestión que se haga del mismo. Con independencia de los cargos, un político debe ganarse el apoyo popular merced a su honestidad y humildad. El uso de adverbios aparece incrustado en espacios retóricos de singular peso argumentativo. Además de subrayar la importancia de pasajes retóricos que Clinton deseaba imprimir en la memoria de sus oyentes, los adverbios también suministraban los matices que deseaba marcar a sus frases. Mediante el uso de ese modificador de modificadores que es el adverbio, el Presidente modulaba ideas y perfilaba proyectos, generalmente para integrar a un auditorio, abarcando en el sentido del discurso a nuevos adhirientes.

El silencio es otro medio táctico en la retórica de Clinton. La capacidad para establecer una corriente de empatía con su público quedaba reforzada mediante pausas calculadas que motivaban, hacían reflexionar y facilitaban una recapitulación en el largo camino que era su discurso político. $\mathrm{Y}$ es que Clinton planteaba su interlocución pública como una 
conversación, pero también como el recorrido de una ruta donde se producían paradas, con nuevas aportaciones y mejoras. Un proceso siempre creciente de enriquecimiento para una narrativa que elevaba el ánimo -y el sentido moral- del oyente, evitando atribularle o asfixiarle en un batiburrillo de datos penosamente conectados entre sí; el Presidente lo era también de los sentimientos y de los objetivos. De ahí que los silencios fuesen tan relevantes en las intervenciones de Clinton. Unos segundos de aparente receso pero que, en realidad, servían al objeto compartido (Presidente y auditorio) de comunicarse entre sí. Miradas cruzadas, gestos empáticos (manos extendidas hacia un público que aplaude o ríe, siente y vive con su líder). Aun salvando las enormes distancias que se daban entre las dos imágenes, resulta pertinente aprender de las lecciones del soberbio estudio de la figura del director de orquesta (o algo más) que, en su momento y con enorme talento, realizase Elias Canetti.

La intensísima mirada del director abarca toda la orquesta, cada uno de cuyos integrantes se siente observado por él, pero sobre todo escuchado. Las distintas partes instrumentales son las opiniones y convicciones a las que el director presta la máxima atención. Es omnisciente, pues mientras que los músicos tienen delante solo sus partes instrumentales, él tiene la partitura completa en la cabeza o en su atril. Sabe con toda exactitud qué le está permitido a cada uno en cada momento. El hecho de que preste atención a todos juntos le confiere el don de la omnipresencia (Canetti, 2002:511).

El Presidente controlaba los tiempos de su discurso, asignando roles a las palabras. Clinton comprendía perfectamente que los mensajes arrastran alegorías e ideas; toda persona, incluso en una democracia avanzada, necesita de iconos para alimentar el espíritu de la libertad. La distinción entre representación y símbolo de Hanna Pitkin adquiere especial relevancia en la práctica retórica aplicada por Clinton. Éste personalizaba la representación en un aspecto formal determinado, pero también ejerció el papel de símbolo -olítico y cívico, nacional y social- hasta trascender el propio significado literal de su discurso hablado.

Nunca podemos agotar ni captar totalmente en palabras la totalidad de lo que un símbolo simboliza: sugiere, evoca, insinúa. Es la única encarnación posible de lo que simboliza (Pitkin, 1985:106).

Ese líder de la empatía que representó Clinton implicaba estar al tanto de cada detalle. Controlaba la situación, sin abusar de su autoridad ni coartar la libertad de otros potenciales intervinientes. En un debate público sobre medicina pública, el introductor cometió un error al afirmar We're going to go to our first question tonight from Bristol, Connecticut, Mr. President. Éste le corrigió con precisión: “Bristol, Tennessee" (Clinton, 1994d:583). No se puede decir más en menos. Una habilidad prototípica: su habilidad para repentizar y jerarquizar información, junto a su sentido de la oportunidad para saber administrarla. El discurso del Presidente era una invitación continua para mejorar el mundo. To Change the World. Aunque la retórica de Clinton expresó ideas precisas y difusas desde el principio, en lo referido a la regeneración democrática el Presidente impulsó un discurso nítido. La franqueza, la sinceridad, son indispensables al dirigirse a una audiencia, pero no suficientes. También cuenta la verosimilitud de aquello que se dice como expresión de una convicción hondamente sentida. En ocasiones, Clinton adoptaba una estrategia dual, en el sentido de abrir fisuras ideológicas entre derecha e izquierda 
para, en el momento político adecuado, presentarse él mismo como el único capaz de resolver la escisión. El Presidente alentaba la disfunción para, luego, insuflar el antídoto. De ahí su preferencia en hacer permanente campaña sobre ambos espacios ideológicos. Así, Clinton emergía como figura con pleno sentido de la realidad; mérito éste reconocido también por el centro-derecha.

Clinton procedió de facto a la refundación del Partido Demócrata, mediante la gestión de un amplio espectro ideológico, que abarcaba desde las bases tradicionales del centroizquierda liberal hasta englobar también a republicanos moderados, atraídos por la transversalidad ideológica -y el pragmatismo operativo- del Presidente. De ahí que la Casa Blanca ganase para sí un cúmulo de votos, que iban más allá de una posición doctrinal rígida; la elasticidad se impuso y el Presidente hizo de la transacción, de la atracción, mecanismos de su acción pública. Clinton ya esbozó -antes que Blair- por la vía de los hechos, no de la formulación teórica dogmática, la consecución de una tercera vía que superase a la izquierda, así como a la derecha, en tanto fuerzas políticas mutuamente excluyentes.

En el surco intelectual del aristotelismo, Clinton adoptaba lo mejor de cada ámbito, reconvirtiéndose a la política mesocrática y ecléctica. El sincretismo, factor decisivo para lograr la transversalidad y la utilidad. De ahí que la recuperación del mensaje de centro, liberal y progresista a la vez -con servicios públicos y economía libre caminando de la mano- fuese un éxito histórico para consolidar su presidencia. La clave reposaba en la destreza para transmitir -y cumplir- obligaciones contraídas; Clinton propuso y respaldó un contrato ético para cada ciudadano. Sin embargo, el discurso era reformulado de tal manera que esa figura contractual se ofrecía a la sociedad civil como un acuerdo casi personal entre el Presidente y el ciudadano, cada ciudadano. Se trataba, en definitiva, de actuar como explorador de la civilización, prospectando el nuevo territorio político -y el antiguo- al objeto de conseguir mejores condiciones para todos. Ser capaz de to identify significant areas of agreement (Clinton, 1996b). Cabal reflejo de su implicación personal en toda decisión política que adoptaba, Clinton aparecía como guía hacia la tierra prometida, haciendo posible otra vez el American Dream.

Si bien en su política práctica, del día a día, Clinton realmente no inventó nada en materia de comunicación política, también es cierto que su habilidad como líder social estuvo en su capacidad para ordenar un magma de elementos hasta conferirles una estructura, un sentido. En este contexto surgió su programa de liberalismo social en tanto compromiso ético suscrito con todos y cada uno de los ciudadanos de América. Un contrato -en vigor desde su toma de posesión como Presidente- y cuya única cláusula resolutoria requería el acuerdo de ambas partes (como Clinton recordó con motivo del proceso de destitución iniciado en su segundo mandato). Esa dimensión ética que imprimió a su política se traducía en medidas como mayor seguridad, programas de apoyo a la familia... en definitiva, ponerse al servicio de los ciudadanos. El Presidente exigía respeto para todos; ese buen clima social revertía en beneficio de la comunidad, entendida ésta como un espacio de encuentro y conciliación. Cultura, ética, comunidad, individuo... sólo Clinton podía conseguir la reunión de tales nutrientes bajo un mismo paraguas operativo, que no necesariamente ideológico. En su discurso, Clinton evitaba cuidadosamente emplear frases negativas para hablar de lo propio. La asertividad positiva se basa en lo que realmente queremos conseguir, y los medios para lograrlo. De ahí su énfasis en lo que vamos a hacer -entre todos- en beneficio común; desde el tiempo presente y en beneficio de la siguiente generación, al decir: 
We have reduced the size of the Government more than our counterparts in the other party, reduced the size of regulation. We have led the way toward a lot of changes, through the Vice President's efforts, that needed to be made. But we do not believe that that which we do together through our Government is the enemy of America and its future. We believe we have to work together to make the most of the future. That's why we're here tonight (Clinton, 1997a).

La idea de herencia se transmutó, en manos de Clinton, en un hábil resorte apelativo que se fundía con ese amanecer soñado -ansiado, compartido- de Estados Unidos que sus compatriotas esperan. El Presidente vendía espléndidamente una promesa irredenta, donde lo recibido se trocaba en patrimonio a mejorar para su entrega a la siguiente generación. Un país que funcionaba, y una democracia que repartía dividendos entre sus ciudadanos. La herencia -ese acervo de valores éticos y políticos- nos obligaba como demócratas, y nos impulsaba como personas cívicas. Ni un paso atrás; la libertad de cada uno es la última frontera, infranqueable para los amigos de la dictadura, de la destrucción del sistema de asistencia social, o de la invasión en nuestra sacrosanta vida privada. El patrimonio que nos entregaron las generaciones anteriores, de acuerdo a la visión de Clinton, no estaba constituido únicamente por elementos materiales, sino también por hechos morales, ejemplos personales y valores éticos. Una teología política que se alimentaba a sí misma con el esfuerzo y el trabajo de nuevos patriotas norteamericanos, dispuestos a la ejemplaridad que comporta la solidaridad entre todos.

El discurso de proximidad tiene permite establece lazos de empatía con aquello que nos es más familiar, sea en el lenguaje, la ideología, los gustos, u otro ámbito. La afinidad era buscada por el Presidente evitando un vocabulario demasiado elaborado; de ahí la elusión de cultismos angostos o expresiones ampulosas, al tiempo que se depuraba del vocabulario político toda interpretación polémica que pudiera molestar siquiera a una parte de la audiencia. El esfuerzo mayor de un orador suele residir en distribuir correctamente sus argumentos, evitando el agotamiento del oyente pero procurando su encantamiento retórico.

Los programas de empleo marcaban las prioridades del Gobierno federal; y éste los dotaba económicamente para conseguir efectos positivos sobre los mercados. En realidad, la clave pasaba por expandir una imagen de eficiencia técnica y de humanidad emocional sin interferencias entre ambas dimensiones, complementándose entre sí-. Lo primero sin lo segundo, aporta únicamente prestigio, a lo sumo cierta fiabilidad, pero no legitimidad. Además de una sólida obra de gobierno, resulta indispensable conectar emocionalmente con la ciudadanía a la que se destina esa labor. La vocación empática del Presidente estaba justificada -y arraigada- en un empirismo político (practical idealism) manifestado tanto en el lenguaje, las técnicas, los medios y hasta los fines. Raramente Clinton hablaba de egoísmo o de insolidaridad; prefería centrarse en términos abiertos y evocadores: generosidad, futuro, libertad, prosperidad, bienestar, etc. En Estados Unidos, el idioma de la democracia, junto a las realidades y los hechos, también se construye con imágenes, incluso ensoñaciones.

En el discurso de Clinton, los estudiantes representan el futuro, la mejor garantía para la sociedad. De ahí que las becas y demás ayudas sociales apareciesen como un complemento indispensable para dotar de contenido a las declaraciones formales. Obviamente, se trataba también de una metáfora para defender las políticas públicas que impulsaba su Administración. El de Clinton fue un Gobierno con verdadero interés social, 
demostrándose además que, al mismo tiempo, era factible la reducción del déficit fiscal hasta alcanzar superávit en el presupuesto.

Significant delays in implementing distribution of humanitarian goods-caused, in part, by Iraqi efforts to impose new restrictions on the freedom of access and movement of U.N. monitors- made it impossible for the U.N. Secretary General to report on the adequacy of distribution and monitoring procedures during the first 90 days. We will continue to monitor the situation closely (Clinton, 1997b).

\section{CONCLUSIONES.}

El mensaje emitido desde la Casa Blanca era que la buena administración de los recursos públicos permitía atender las necesidades perentorios de las clases humildes. La redistribución de la riqueza significaba, para Clinton, la asignación de medios para cumplir el mandato moral de su liberalismo social. La pobreza era una ofensa a la sociedad norteamericana, afirmó el Presidente; tenemos el deber moral y cívico de aliviar (y, de si fuera posible, de erradicar) el sufrimiento de ese Tercer Mundo que coexiste en Estados Unidos con el resto de sus conciudadanos. Un país occidental, más si cabe cuando se trata de la única superpotencia mundial, no puede tolerar que dentro de sus fronteras se den situaciones que atentan contra los mismos Derechos Humanos. La lucha contra la miseria, contra la exclusión social, era para el Presidente una obligación ética, derivada de la misma esencia del concepto de humanidad. De ahí su decisión de apoyar financieramente las instituciones asistenciales que aportaban ayuda directa. Centros sanitarios, dependencias públicas, escuelas primarias... y la emisión de una tarjeta sanitaria de ámbito nacional que consolidase los programas de la Sanidad pública a favor de los desfavorecidos. El combate de la Casa Blanca para conseguir la aprobación de esta última medida fue planteada -en la primera etapa de la Administración Clinton- desde una posición más agresiva que dialogante $\mathrm{y}$, consecuentemente, la iniciativa presidencial sufrió un correctivo en su tramitación parlamentaria. El carácter bisoño de la Administración Clinton, su descarnado idealismo progresista -fundamentalmente impulsado por la Primera Dama- activó una reacción contraria entre las filas republicanas -que incluso contaron con apoyos de parlamentarios moderados del Partido Demócrata-; la oposición jaleó el fantasma de un Gobierno dirigista de funciones del Congreso e invasor de la libertad de decisión del ciudadano. Clinton pudo constatar que el supuesto intervencionismo gubernamental era presentado por sus antagonistas como efecto ineluctable de una mentalidad con ínfulas de despotismo ilustrado, que deseaba la imposición, no la negociación.

La idea de devolución desempeñó un papel conscientemente tamizada en la iconología presidencial. Clinton se comprometió, de manera personal, a devolver a los ciudadanos lo que Gobiernos anteriores les habían detraído por mor de programas directos, o acciones indirectas. Imbuido de vocación mesocrática, Clinton se presentó como un paladín de las clases medias; el único capaz de sortear las inclemencias de la tempestad, que es resultado de la inseguridad ciudadana y la volatilidad económica. Asimismo, la acción presidencial enfatizó contra el intervencionismo privado sobre la sociedad civil. Que los ciudadanos tomen las riendas de sus propias decisiones, erradicándose para siempre el dirigismo comercial o económico, así como, igualmente pernicioso, la intromisión de las corporaciones industriales que invaden la vida de las clases medias; éstas fueron el centro y motor de la actividad de Clinton. Recae sobre los sectores medios la función suprema de 
recuperar la iniciativa del país y de la política. Las reformas de Clinton propendían a la eliminación de barreras para que la sociedad, los ciudadanos, regenerasen, dirigiesen su patria democrática. Emprender el camino para que todos asumiesen su responsabilidad exigía la toma de conciencia que el Presidente impulsaba.

You and I know that unless people do the right things themselves that we can't solve the problems of our society. And I was calling for a devolution of responsibility back to local and State governments long before I ever ran for President. So these are not just issues of a political season for me (Clinton, 1995a).

Clinton creó un clima propicio al reformismo social. En tales circunstancias, el Presidente podía implantar una idea de empresa colectiva, en verdad única, llamada sociedad democrática, en condiciones de acometer las exigencias crecientes del tercer milenio. Al tiempo que se daban necesidades de protección y amparo, la Administración debía satisfacer tales demandas de la ciudadanía. Se trataba, por tanto, de fomentar una intensa social fabric para evitar el surgimiento de poderes paralelos (políticos, económicos, etc.) que puedan superponerse al demos. El paradigma del tiempo presente, sostenía Clinton, es el mismo cambio. Éste en sí ha sustituido toda veleidad rupturista para erigirse en manifestación de la continuidad. El cambio arrostra un desafío para todos; un campo abierto donde el conjunto de la sociedad debe asumir sus responsabilidades y mostrar lo mejor de sí misma. Cambiar para volver a la América de siempre y de ahora... en el porvenir. El cambio es modernización, pero también restauración de los valores universales que inspiraban, desde siempre, el espíritu norteamericano. La idea de modernización, empleada como base de la retórica presidencial, tuvo a su primer cultivador en la figura de James Madison. El principal autor de la Constitución (aunque un fluctuante ejecutor de la misma durante su etapa como Presidente de 1809 a 1817), consiguió incorporar a la ideología oficial que destilaba la Casa Blanca, tras la energética Administración Jefferson, la idea de modernidad como objetivo en sí mismo (Wills, 2002: 155). Un idealismo humanista que Clinton recuperó para sí y para sus compatriotas. La cultura del cambio no era un paso hacia delante a toda costa; se trata de innovar, de mejorar, de escalar, de alcanzar nuevos niveles en la marcha de la vida para beneficio de todos, conservando lo mejor de nuestro patrimonio social y de nuestro acervo cultural. El ciudadano era el heredero ético de las generaciones anteriores, y el garante de lo que han de recibir nuestros descendientes.

If we are going to rescue our children's future, we have to do a number of things. We have to grow the middle class and shrink the under class. We have to support policies that reinforce work and families and communities. We have to change the way the Government operates so that it promotes independence, not dependence, opportunity and not bureaucracy. We have to give our youngest children things that they can't guarantee for themselves (Clinton, 1995b).

\section{BIBLIOGRAFÍA}

BARBER, J. D. (1992), The presidential character: predicting performance in the White House, Englewood Cliffs, Prentice Hall.

CANETTI, E. (2002), Masa y poder, Barcelona, Círculo de Lectores. 
CLINTON, B. (1993a), "Nomination for Ambassador to the Organization for Economic Cooperation and Development", 26 de abril de 1993. En: http://www.presidency.ucsb.edu/ws/index.php?pid=46485 \&st=\&st1=, Consulta: 28/10/2012.

CLINTON, W. J. (1993b), "Message on National African-American History Month", 1 de febrero de 1993. En: http://www.presidency.ucsb.edu/ws/index.php?pid=46566\&st=After + considering + the + matt er\%2C+the+National+Archives\&st1=, Consulta: 11/8/2012.

CLINTON, W. J. (1994a), "Joint Statement on Economic and Commercial Cooperation", 4 de marzo de 1994 (suscrito por Ucrania y Estados Unidos). En: http://www.presidency.ucsb.edu/ws/index.php? pid=49757\&st $=\&$ st $1=$, Consulta: $9 / 10 / 2012$.

CLINTON, W. J. (1994b), "Joint Statement on Development of U.S.-Ukrainian Friendship and Partnership", 4 de marzo de 1994 (suscrito por Ucrania y Estados Unidos). En: http://www.presidenc y.ucsb.edu/ws/index.php?pid=49756, Consulta: 1/10/2012.

CLINTON, W. J. (1994c), "Partnership for Economic Progress: Joint Statement on Principles and Objectives for the Development of Trade, Economic Cooperation, and Investment", 28 de septiembre de 1994 (suscrito por Rusia y Estados Unidos). En: http://www.presidency.ucsb.edu/ws/index.php?pid= 49173\&st=\&st1=, Consulta: $1 / 10 / 2012$.

CLINTON, W. J. (1994d), "Remarks in a Town Meeting in Charlotte, North Carolina", 5 de abril de 1994 (PPPUS, 1994).

CLINTON, W. J. (1995a), "Teleconference Remarks With the U.S. Conference of Mayors", 20 de junio de 1995. En: http://www.presidency.ucsb.edu/ws/index.php?pid=51510\&st=devoluti on\&st1=, Consulta: 22/9/2012.

CLINTON, W. J. (1995b), "Remarks to the National Governors' Association Summit on Young Children in Baltimore, Maryland", 6 de junio de 1995. En: http://www.presidency.ucsb.edu/ws/index.p hp?pid $=51451 \&$ st $=$ change\&st $1=$. Consulta: $22 / 9 / 2012$.

CLINTON, W. J. (1996a), "Letter to Congressional Leaders on the Comprehensive Trade and Development Policy for Africa", 5 de febrero de 1996. En: http://www.presidency.ucsb.edu/ws/index. php?pid=52178\&st=\&st1=, Consulta: 7/10/2012.

CLINTON, W. J. (1996b), "Remarks to the National Governors' Association Conference", 6 de febrero de 1996. En: http://www.presidency.ucsb.edu/ws/index.php?pid=52200\&st=agreement\&st1=, Consulta: 2/9/2012.

CLINTON, W. J. (1997a), "Remarks at a Democratic Senate Campaign Committee Dinner in New York City", 18 de febrero de 1997. En: http://www.presidency.ucsb.edu/ws/index.php?pid=53757\&st= we+do+together\&st1 $=$, Consulta: 2/9/2008.

CLINTON, W. J. (1997b), "Letter to Congressional Leaders on Iraq", 8 de mayo de 1997. En: http://www.presidency.ucsb.edu/ws/index.php?pid=54121\&st=distribution\&st1=, Consulta: 22/9/2012.

CLINTON, W. J. (1998a), "United States-European Union Statement on Cooperation in the Global Economy", 18 de diciembre de 1998. En: http://www.presidency.ucsb.edu/ws/index.php?pid=55422\&st $=\&$ stl $=$, Consulta: 8/10/2012.

CLINTON, W. J. (1998b), "Statement of European Union/United States Shared Objectives and Close Cooperation on Counter-Terrorism", 18 de mayo de 1998. En: http://www.presidency.ucsb.edu/ws/ind ex.php?pid=55984\&st=\&st1=, Consulta: 4/10/2012.

CLINTON, B. (1999), "Remarks at the Opening of the Organization for Security and Cooperation in Europe Summit in Istanbul”, 18 de noviembre de 1999. En: http://www.presidency.ucsb.edu/ws/index. php?pid=56952\&st=\&st1 $=$, Consulta: $2 / 10 / 2012$.

CLINTON, W.J. (2000), "Joint Statement: Strategic Stability Cooperation Initiative Between the United States of America and Russian Federation", 6 de septiembre de 2000. En: http://www.presiden cy.ucsb.edu/ws/index.php?pid=1392\&st=\&st1=, Consulta: 6/10/2012.

CLINTON, B. (2004a), My Life, Nueva York, Alfred A. Knopf.

CLINTON, B. (2007), Giving: how each of us can change the world, Nueva York, Alfred A. Knofp.

EDWARDS, George C. y Stephen J. WAYNE (2009), Presidential Leadership: Politics and Policy Making, Boston, Wadsworth Publishing.

HAMILTON, N. (2007), Bill Clinton: Mastering the Presidency, Nueva York, Public Affairs. 
MCLOUGHLIN, M. (ed.) y BESCHLOSS, M. (1999), The impeachment and trial of President Clinton: the official transcripts, from the House Judiciary Committee hearings to the Senate trial, Nueva York, Times Books.

MILL, J. S. (1996), Sobre la libertad: comentarios a Tocqueville, Madrid, Espasa-Calpe.

NIXON, R. (1989), 1999. Victoria sin guerra, Barcelona, Editorial Planeta.

PFIFFNER, J. P. (1999), The Managerial Presidency, College Station, Texas A\&M University Press. PITKIN, H. F. (1985), El concepto de representación, Madrid, Centro de Estudios Constitucionales. WILLS, G. (2002), James Madison, Nueva York, Times Books (Henry Holt and Company).

\section{Breve currículo}

\section{José J. Sanmartín Pardo}

Profesor Titular: Universidad de Alicante. Doctor en Filosofía, Universidad de Murcia. Doctor en Ciencia Política y Sociología por la UNED. Máster en Gestión y Análisis de Políticas Públicas por la Universidad Carlos III de Madrid. Máster en Derecho de la Unión Europea por la UNED. Diversos Diplomas de Especialización como: Derecho Constitucional y Ciencia Política; Comunidades Europeas; Relaciones Internacionales y Cooperación. Socio perpetuo (Lifetime Member) de American Political Science Association, International Political Science Association, American Historical Association, entre otras. Investigador en diversas Universidades; Harvard University (USA), McGill University (Canadá), Università "La Sapienza", Roma (Italia), Dublin (Irlanda), Lisboa (Portugal), Oxford (Reino Unido), etc. Seagram International Fellow, McGill University, Montreal (Canadá). Autor de más de cincuenta publicaciones científicas indexadas. 